\title{
Intermediate Species Profiles in Low-Pressure Methane/Oxygen Flames Inhibited by 2-H Heptafluoropropane: Comparison of Experimental Data with Kinetic Modeling
}

\author{
BRADLEY A. WILLIAMS*, DREW M. L' ESPÉRANCE, AND JAMES W. FLEMING \\ Chemistry Division, Naval Research Laboratory, Washington, DC 20375-5342
}

\begin{abstract}
Experimental profiles of the intermediate species $\mathrm{H}, \mathrm{OH}, \mathrm{CH}, \mathrm{CF}, \mathrm{CF}_{2}$, and $\mathrm{CHF}$ are obtained in a 10 torr premixed flat flame of methane/oxygen in a 1:2 molar ratio, inhibited by a $4 \%$ mole fraction of $2-\mathrm{H}$ heptafluoropropane ( $\mathrm{HFP}, \mathrm{CF}_{3} \mathrm{CHFCF}_{3}$ ). These data are compared to calculations using a recently published kinetic mechanism describing the consumption of this fire suppression agent. The profiles in the flame inhibited by HFP are compared to previously published data for flames containing $\mathrm{CHF}_{3}$ and $\mathrm{CH}_{2} \mathrm{~F}_{2}$ under the same conditions of stoichiometry and flux of fluorine atoms. The species profiles relative to the flames containing the fluoromethanes are accurately predicted and atmospheric pressure flame speeds are fairly well predicted by the kinetic mechanism. Under equal fluorine loadings, profiles of temperature and of $\mathrm{H}$ and $\mathrm{OH}$ mole fraction are virtually identical between the flames containing $\mathrm{HFP}$ and $\mathrm{CHF}_{3}$. The flame inhibited by HFP, however, has approximately twice as much $\mathrm{CH}^{*}$ emission as the flame containing $\mathrm{CHF}_{3}$. The kinetic model predicts that thermal decomposition, rather than $\mathrm{H}$ atom abstraction, is the primary destruction mechanism for HFP under the conditions studied. (C) 1999 by The Combustion Institute
\end{abstract}

\section{INTRODUCTION}

2-H heptafluoropropane (commonly referred to as HFP or HFC-227ea, having the chemical structure $\mathrm{CF}_{3} \mathrm{CHFCF}_{3}$ ) is coming into widespread use as a fire suppressant [1] to replace brominated compounds such as Halon 1301 $\left(\mathrm{CF}_{3} \mathrm{Br}\right)$, whose production has been prohibited in developed countries by international treaty. Due to the practical importance of HFP in fire protection, as well as its somewhat lower suppression efficiency than Halon 1301 [2, 3], it is desirable to understand this compound's chemical behavior in flame environments. Of particular importance is the origin and magnitude of suppression due to fluorine chemistry, as opposed to physical effects of the agent's addition to the flame.

A kinetic mechanism for combustion chemistry of $\mathrm{C}_{1}$ and $\mathrm{C}_{2}$ fluorocarbons has been developed at the U.S. National Institute of Standards and Technology (NIST) [4-6]. Recently, our laboratory has published profiles of several intermediate species in premixed low-pressure

\footnotetext{
*Corresponding author. E-mail: brad@code6185.nrl.navy.mil National Research Council Postdoctoral Associate 1995-97. Present address: Department of Physical Sciences, New Mexico Highlands University, Las Vegas, NM 87701-4073.
}

methane/oxygen flames containing the series of fluoromethanes [7]. These experimental data were compared to predictions of the NIST fluorocarbon mechanism, and some refinements to the kinetics were suggested on the basis of validation against both low-pressure species profile data and atmospheric pressure flame speed measurements.

During our experimental study of fluoromethane-inhibited low-pressure flames, we also recorded profiles in a flame inhibited by HFP. These data were not included in Ref. 7, because the fluorine kinetic mechanism did not include any $\mathrm{C}_{3}$ compounds, and only qualitative interpretations of the flame structure could be made. More recently, Hynes et al. proposed a kinetic mechanism [8] for the initial breakdown of HFP into $\mathrm{C}_{1}$ and $\mathrm{C}_{2}$ fragments. When added to the NIST HFC mechanism, the HFP submechanism permits kinetic modeling of HFP-inhibited flames. In Ref. 8, kinetic model predictions were compared to experimental measurements of postflame concentrations of stable species in lean atmospheric pressure hydrogen/air flames inhibited by HFP. Hynes et al. have since published a shock tube study of HFP decomposition in a pyrolytic environment [9], and reported stable species profiles in an atmospheric pressure hydrogen/ethane/air/HFP flame [10].

COMBUSTION AND FLAME 120:160-172 (2000) (C) 1999 by The Combustion Institute Published by Elsevier Science Inc. 
TABLE 1

Flame Conditions

\begin{tabular}{|c|c|c|c|c|c|c|}
\hline \multirow[b]{2}{*}{ Agent } & \multicolumn{3}{|c|}{ Flow Rates $\left(\mathrm{cm}^{3} / \min @ 0^{\circ} \mathrm{C}\right)$} & \multirow{2}{*}{$\begin{array}{l}\text { Adiabatic Flame } \\
\text { Temperature }(\mathrm{K})^{\mathrm{a}}\end{array}$} & \multirow[b]{2}{*}{$\phi$} & \multirow{2}{*}{$\begin{array}{c}\text { Mass Flow } \\
\left(\mathrm{g} / \mathrm{cm}^{2}-\mathrm{s}\right)\end{array}$} \\
\hline & $\mathrm{CH}_{4}$ & $\mathrm{O}_{2}$ & Agent & & & \\
\hline none & 400 & 800 & 0 & 2571 & 1.00 & $0.86 \times 10^{-3}$ \\
\hline $\mathrm{CH}_{2} \mathrm{~F}_{2}$ & 342 & 800 & 175 & 2557 & 1.07 & $1.08 \times 10^{-3}$ \\
\hline $\mathrm{CHF}_{3}$ & 400 & 800 & 117 & 2548 & 1.07 & $1.08 \times 10^{-3}$ \\
\hline $\mathrm{C}_{3} \mathrm{HF}_{7}$ & 400 & 800 & 50 & 2560 & 1.08 & $1.09 \times 10^{-3}$ \\
\hline
\end{tabular}

Profiles of several stable and intermediate species in low-pressure methane/oxygen/argon flames inhibited by HFP were presented by Battin-Leclerc et al., in Ref. 1. The profiles were compared to those of an uninhibited flame, and a flame inhibited by $\mathrm{C}_{2} \mathrm{~F}_{6}$. The experimental flame structure gave reasonable agreement with predictions of a kinetic model taken from the work of Westbrook [11] on inhibition by $\mathrm{CF}_{3} \mathrm{Br}$, with some additional steps added to account for the initial breakdown of the inhibitor into $C_{1}$ fluorinated species. In the present study we use the NIST kinetic mechanism as a starting point, since it is more comprehensive than the mechanism of Westbrook especially in terms of $\mathrm{C}_{2}$ chemistry. Hynes et al. developed their HFP submechanism using the NIST mechanism to describe the $\mathrm{C}_{1}$ and $\mathrm{C}_{2}$ fluorocarbon kinetics.

Here we compare the predictions of the HFP kinetic mechanism (the $\mathrm{C}_{3}$ submechanism of Hynes et al. [8-10] added to the HFC mechanism revised according to Ref. 7), with experimental species profiles. The flame conditions of our study are quite different from those in Ref. 8 , having considerably higher peak temperatures, slightly rich stoichiometry, and hydrocarbon fuel, as well as being at reduced pressure. We validate the combined mechanism against the atmospheric pressure flame speed data of Linteris et al. [12], who investigated premixed methane/air flames inhibited by several fluoroethanes and fluoropropanes, including HFP. Kinetic modeling predictions of adiabatic flame speeds were reported in Ref. 12 for the mixtures containing fluoroethanes but not fluoropropanes. We compare modeling predictions of the present mechanism with those of Hynes et al. presented in Ref. 10. Based on comparison of the model predictions to the experimental data sets, we suggest some refinements to the $\mathrm{C}_{2}$ chemistry in the NIST HFC mechanism.

\section{EXPERIMENTAL}

The experimental apparatus and procedures were identical to those used in our study on flames containing fluoromethanes [7]. The HFP-inhibited flame maintained at 10 torr consisted of a stoichiometric methane/oxygen mixture with $4 \%$ mole fraction of HPF added. This flame contained an equal number of fluorine atoms as the flame inhibited by $8.9 \%$ mole fraction of trifluoromethane, the standard condition for this agent used in Ref. 7. The overall equivalence ratio (taking into account the agent) was also nearly identical, $\phi=1.08$ compared to 1.07 for the flame containing $8.9 \%$ $\mathrm{CHF}_{3}$. Flow conditions of the HFP-inhibited flame, as well as the uninhibited flame and flames inhibited by $\mathrm{CHF}_{3}$ and $\mathrm{CH}_{2} \mathrm{~F}_{2}$ used for comparison of intermediate species profiles, are listed in Table 1.

The flame species $\mathrm{H}, \mathrm{OH}, \mathrm{CH}, \mathrm{CF}, \mathrm{CHF}$, and $\mathrm{CF}_{2}$ were monitored by laser-induced fluorescence; the detection schemes for these species are listed in Table 2, and have been more completely described previously [7, 13]. Flame temperature profiles were determined from laser-induced fluorescence (LIF) spectra of the $\mathrm{OH}$ radical. Profiles of $\mathrm{CH}^{*}$ chemiluminescence at $430 \mathrm{~nm}$ were also recorded. All species profiles were measured on a relative basis. Profiles from an appropriate reference flame (uninhibited, $\mathrm{CHF}_{3}$-inhibited, or $\mathrm{CH}_{2} \mathrm{~F}_{2}$-inhibited) were recorded in immediate succession to those in the flame inhibited by HFP, so that the relative concentrations of the radical species for the different flame conditions can be directly compared. The structure and chemistry of the flames inhibited by fluoromethanes is discussed elsewhere [7]; the present study is focused on the structure of the HFP-inhibited flame in 
TABLE 2

Optical Diagnostics Used for Detection of Flame Species

\begin{tabular}{|c|c|c|c|c|}
\hline Species & Transition & $\begin{array}{c}\text { Excitation } \\
\text { Wavelength } \\
(\mathrm{nm})\end{array}$ & $\begin{array}{c}\text { Excitation } \\
\text { Energy } \\
(\mu \mathrm{J})\end{array}$ & $\begin{array}{c}\text { Emission } \\
\text { Wavelength } \\
(\mathrm{nm})\end{array}$ \\
\hline $\mathrm{H}$ & $1 \mathrm{~s}-2 \mathrm{~s}-4 \mathrm{p}$ (3 photon) & $\begin{aligned} & 243.1 \text { (2-photon) } \\
+ & 486.1\end{aligned}$ & $\begin{array}{r}150 \\
10\end{array}$ & 486 \\
\hline $\mathrm{OH}$ & $\mathrm{R}_{1}(8) \mathrm{A}-\mathrm{X}(1,0)$ & 281.27 & 30 & 311 \\
\hline $\mathrm{CH}$ & $\mathrm{Q}_{1}(6) \mathrm{B}-\mathrm{X}(0,0)$ & 389.98 & 200 & 390 \\
\hline $\mathrm{CF}$ & $\begin{array}{l}\mathrm{Q}_{2}(21.5)+\mathrm{P}_{1}(26.5)+ \\
\mathrm{Q}_{1}(19.5) \mathrm{A}-\mathrm{A}(1,0)\end{array}$ & 223.30 & 200 & $255 \pm 15$ \\
\hline $\mathrm{CF}_{2}$ & $A-X$ & 250 & 60 & $334 \pm 20$ \\
\hline $\mathrm{CHF}$ & $A-X(0,3,0)-(0,0,0)$ & 492.42 & 300 & $>515 \mathrm{~nm}$ \\
\hline
\end{tabular}

comparison to those containing the $\mathrm{C}_{1}$ compounds.

LIF profiles were obtained by correcting the measured LIF signal for changes in the intensity of the laser used to excite fluorescence. The corrected LIF profiles have been converted to species mole fraction by correcting for gas density changes and the temperature dependence of the ro-vibronic level probed. For the species $\mathrm{CHF}$ the correction is very uncertain because the rotational structure has not been completely analyzed, and interference is present in the region between 5-10 $\mathrm{mm}$ above the burner.

The LIF signals have not been corrected for quenching variations between flames. The fluorescence signal was integrated over an interval of approximately $20 \mathrm{~ns}$ immediately following the laser pulse to minimize the influence of quenching. For most species probed, fluorescence lifetimes were on the order of 150-200 ns for all flame conditions. The only exceptions are $\mathrm{CF}$ and $\mathrm{CF}_{2}$, which have short fluorescence lifetimes $(<50 \mathrm{~ns})$ due to radiative decay and predissociation, and hence are relatively unaffected by quenching. We estimate the experimental uncertainties in the ratios of LIF signals between different flames to be $\pm 10 \%$.

\section{KINETIC MECHANISM AND MODELING}

The chemical structures of the inhibited flames were modeled using the Sandia PREMIX and related codes [14-16]. The kinetic mechanism and thermodynamic database used for the $\mathrm{H} / \mathrm{C} / \mathrm{O}$ chemistry for one-carbon and two-carbon species was the Gas Research Institute
GRI-Mech 2.11 [17], with nitrogen chemistry deleted. The NIST HFC mechanism, as refined in Ref. 7, was used for the thermodynamics and reactions of the $\mathrm{C}_{1}$ and $\mathrm{C}_{2}$ fluorinated species. This mechanism gave good agreement with both flame speed measurements and species profiles of methane flames containing fluoromethanes [7]. For the initial breakdown of HFP, the reaction set from Ref. 8 was used as the starting point.

This mechanism detailed above was modified in the following ways (Table 3). First, the original NIST HFC mechanism did not include reactions of the $\mathrm{CF}_{3}$ - $\mathrm{CHF}$ radical (a major thermal decomposition product of HFP) with atomic hydrogen. In Ref. 12 kinetics for two product channels of this reaction were proposed, as were revised kinetics for a few other reactions. We adopted four of the reactions proposed in Ref. 12, including the two $\mathrm{CF}_{3}-\mathrm{CHF}+\mathrm{H}$ reactions. The rate expressions from Ref. 9 were used for the HFP thermal decomposition reactions (numbers refer to Table 3)

$$
\begin{aligned}
& \mathrm{CF}_{3} \mathrm{CHFCF}_{3} \Rightarrow \mathrm{CF}_{3} \mathrm{CHF}+\mathrm{CF}_{3}, \\
& \mathrm{CF}_{3} \mathrm{CHFCF}_{3} \Rightarrow \mathrm{CF}_{3} \mathrm{CF}=\mathrm{CF}_{2}+\mathrm{HF} .
\end{aligned}
$$

Thermal decomposition for $\mathrm{CF}_{3} \mathrm{CHF}$,

$$
\mathrm{CF}_{3} \mathrm{CHF} \Rightarrow \mathrm{CF}_{2}=\mathrm{CHF}+\mathrm{F} \text {, }
$$

was added to the mechanism, with parameters from Ref. 9. Additional reactions suggested by Hynes et al. [10, 18] for HFP and products (mostly reactions with hydrocarbon radicals) have been added to the reaction set. Finally, additional product channels (discussed in more detail below) were added for the reactions of $\mathrm{O}$ and $\mathrm{OH}$ with $\mathrm{CF}_{2}=\mathrm{CHF}$. 
TABLE 3

Kinetic Mechanism

Mechanism consists of GRI-Mech 2.11, NIST HFC mechanism as revised in Ref. [7], HFP submechanism of Ref. [8], with the following changes:

\begin{tabular}{|c|c|c|c|c|}
\hline \multirow[b]{2}{*}{ Reaction } & \multicolumn{4}{|c|}{ Arrhenius Parameters $k(T)=\mathrm{AT}^{b} \exp \left(-\mathrm{E}_{a} / \mathrm{RT}\right)$} \\
\hline & $A(\mathrm{~mol}, \mathrm{~cm}, \mathrm{~s})$ & $b$ & $E_{a}(\mathrm{cal} / \mathrm{mol})$ & Ref. \\
\hline \multicolumn{5}{|l|}{ 1. $\mathrm{C}_{3} \mathrm{~F}_{7} \mathrm{H}(+\mathrm{M})=\mathrm{CF}_{3}+\mathrm{CF}_{3}-\mathrm{CHF}(+\mathrm{M})$} \\
\hline high-pressure limit & $7.9 \mathrm{E}+15$ & 0.0 & 85,000 & [9] \\
\hline low-pressure limit & $3.46 \mathrm{E}+21$ & 0.0 & 85,000 & $a, b$ \\
\hline \multicolumn{5}{|l|}{ 2. $\mathrm{C}_{3} \mathrm{~F}_{7} \mathrm{H}(+\mathrm{M})=\mathrm{C}_{3} \mathrm{~F}_{6}+\mathrm{HF}(+\mathrm{M})$} \\
\hline high-pressure limit & $7.9 \mathrm{E}+12$ & 0.0 & 69,600 & [9] \\
\hline low-pressure limit & $3.46 \mathrm{E}+18$ & 0.0 & 69,600 & $a, b$ \\
\hline 3. $\mathrm{C}_{3} \mathrm{~F}_{7} \mathrm{H}+\mathrm{CH}_{3}=\mathrm{C}_{3} \mathrm{~F}_{7} \mathrm{CH}_{4}$ & $5.7 \mathrm{E}+10$ & 0.0 & 9,500 & [10] \\
\hline 4. $\mathrm{C}_{3} \mathrm{~F}_{7} \mathrm{H}+\mathrm{C}_{2} \mathrm{H}_{3}=\mathrm{C}_{3} \mathrm{~F}_{7}+\mathrm{C}_{2} \mathrm{H}_{4}$ & $6.0 \mathrm{E}+10$ & 0.0 & 7,000 & {$[18]$} \\
\hline \multicolumn{5}{|l|}{ 5. $\mathrm{C}_{3} \mathrm{~F}_{7}(+\mathrm{M})=\mathrm{CF}_{2}: \mathrm{CF}_{2} \mathrm{CF}_{3}(+\mathrm{M})$} \\
\hline high-pressure limit & $1.0 \mathrm{E}+14$ & 0.0 & 76,000 & [8] \\
\hline low-pressure limit & $4.38 \mathrm{E}+19$ & 0.0 & 76,000 & $a, b$ \\
\hline \multicolumn{5}{|l|}{ 6. $\mathrm{C}_{3} \mathrm{~F}_{7}(+\mathrm{M})=\mathrm{C}_{3} \mathrm{~F}_{6}+\mathrm{F}(+\mathrm{M})$} \\
\hline high-pressure limit & $2.0 \mathrm{E}+14$ & 0.0 & 69,000 & [8] \\
\hline low-pressure limit & $8.75 E+19$ & 0.0 & 69,000 & $a, b$ \\
\hline 7. $\mathrm{CF}_{3}-\mathrm{CHF}+\mathrm{CF}_{3}=\mathrm{C}_{3} \mathrm{~F}_{6}+\mathrm{HF}$ & $7.0 \mathrm{E}+16$ & -1.17 & 4,330 & [18] \\
\hline 8. $\mathrm{C}_{3} \mathrm{~F}_{6}+\mathrm{O}=\mathrm{CF}_{3} \mathrm{COF}+\mathrm{CF}_{2}$ & $5.8 \mathrm{E}+12$ & 0.0 & 2,500 & {$[10]$} \\
\hline \multicolumn{5}{|l|}{ 9. $\mathrm{C}_{3} \mathrm{~F}_{6}(+\mathrm{M})=\mathrm{CF}_{3}+\mathrm{CF}_{2}: \mathrm{CF}(+\mathrm{M})$} \\
\hline high-pressure limit & $3.2 \mathrm{E}+13$ & 0.0 & 105,600 & [8] \\
\hline low-pressure limit & $1.4 \mathrm{E}+19$ & 0.0 & 105,600 & $a, b$ \\
\hline \multicolumn{5}{|l|}{ 10. $\mathrm{C}_{3} \mathrm{~F}_{6}(+\mathrm{M})=\mathrm{CF}_{2}: \mathrm{CF}_{2}+\mathrm{CF}_{2}(+\mathrm{M})$} \\
\hline high-pressure limit & $3.2 \mathrm{E}+13$ & 0.0 & 94,000 & [8] \\
\hline low-pressure limit & $1.4 \mathrm{E}+19$ & 0.0 & 94,000 & $a, b$ \\
\hline 11. $\mathrm{CF}_{3} \mathrm{CHO}+\mathrm{CH}_{3}=\mathrm{CF}_{3} \mathrm{CO}+\mathrm{CH}_{4}$ & $1.0 \mathrm{E}+11$ & 0.0 & 7,400 & [18] \\
\hline \multicolumn{5}{|l|}{ 12. $\mathrm{CF}_{3} \mathrm{CHO}(+\mathrm{M})=\mathrm{CF}_{2} \mathrm{CO}+\mathrm{HF}(+\mathrm{M})$} \\
\hline high-pressure limit & $1.0 \mathrm{E}+13$ & 0.0 & 30,000 & [8] \\
\hline low-pressure limit & $8.75 E+18$ & 0.0 & 30,000 & $a, b$ \\
\hline \multicolumn{5}{|l|}{ 13. $\mathrm{CF}_{3} \mathrm{CHO}(+\mathrm{M})=\mathrm{CF}_{3}+\mathrm{HCO}(+\mathrm{M})$} \\
\hline high-pressure limit & $4.0 \mathrm{E}+16$ & 0.0 & 80,000 & [8] \\
\hline low-pressure limit & $3.5 \mathrm{E}+21$ & 0.0 & 80,000 & $a, b$ \\
\hline \multicolumn{5}{|l|}{ 14. $\mathrm{CF}_{3} \mathrm{COF}(+\mathrm{M})=\mathrm{CF}_{3}+\mathrm{CF}: \mathrm{O}(+\mathrm{M})$} \\
\hline high-pressure limit & $4.3 \mathrm{E}+16$ & 0.0 & 90,000 & [8] \\
\hline low-pressure limit & $3.76 \mathrm{E}+21$ & 0.0 & 90,000 & $a, b$ \\
\hline 15. $\mathrm{CF}: \mathrm{O}+\mathrm{CHF}_{2}=\mathrm{CF}_{2} \mathrm{CO}+\mathrm{HF}$ & $2.7 \mathrm{E}+13$ & 0.0 & 20,000 & [12] \\
\hline 16. $\mathrm{CF} 3-\mathrm{CHF}+\mathrm{H}=\mathrm{CHF}: \mathrm{CF}_{2}+\mathrm{HF}$ & $6.56 \mathrm{E}+24$ & -3.57 & 4,225 & [12] \\
\hline 17. $\mathrm{CF} 3-\mathrm{CHF}+\mathrm{H}=\mathrm{CH} 2 \mathrm{~F}+\mathrm{CF} 3$ & $4.28 \mathrm{E}+16$ & -0.74 & 4,750 & {$[12]$} \\
\hline 18. $\mathrm{HCO}+\mathrm{CF}_{3}=\mathrm{CF}_{2} \mathrm{CO}+\mathrm{HF}$ & $2.7 \mathrm{E}+13$ & 0.0 & 0 & {$[12]$} \\
\hline \multicolumn{5}{|l|}{ 19. $\mathrm{CF}_{3}-\mathrm{CHF}(+\mathrm{M})=\mathrm{CHF}: \mathrm{CF}_{2}+\mathrm{F}(+\mathrm{M})$} \\
\hline high-pressure limit & $6.3 \mathrm{E}+14$ & 0.0 & 62,000 & [9] \\
\hline low-pressure limit & $5.51 \mathrm{E}+19$ & 0.0 & 62,000 & $a, b$ \\
\hline 20. $\mathrm{CHF}: \mathrm{CF}_{2}+\mathrm{O}=\mathrm{CF}_{2}+\mathrm{CHF}: \mathrm{O}$ & $3.21 \mathrm{E}+06$ & 2.0 & 0 & $a$ \\
\hline 21. $\mathrm{CHF}: \mathrm{CF}_{2}+\mathrm{O}=\mathrm{CHF}+\mathrm{CF}_{2}: \mathrm{O}$ & $3.2 \mathrm{E}+06$ & 2.0 & 2,000 & $a$ \\
\hline 22. $\mathrm{CHF}: \mathrm{CF}_{2}+\mathrm{OH}=\mathrm{CF}_{2}: \mathrm{O}+\mathrm{CH}_{2} \mathrm{~F}$ & $2.0 \mathrm{E}+06$ & 2.0 & 2,850 & $a$ \\
\hline 23. $\mathrm{CHF}: \mathrm{CF}_{2}+\mathrm{OH}=\mathrm{CHF}: \mathrm{O}+\mathrm{CHF}_{2}$ & $4.0 \mathrm{E}+06$ & 2.0 & 2,850 & $a$ \\
\hline
\end{tabular}

${ }^{a}$ Estimated, see text.

${ }^{b}$ Third-body efficiencies: $\mathrm{H}_{2} \mathrm{O}: 9.0, \mathrm{CH}_{4}: 2.0, \mathrm{CO}: 1.5, \mathrm{CO}_{2}: 2.0, \mathrm{C}_{2} \mathrm{H}_{6}: 3.0, \mathrm{CH}_{3} \mathrm{~F}: 6.0, \mathrm{CH}_{2} \mathrm{~F}_{2}: 6.0, \mathrm{CHF}_{3}: 6.0, \mathrm{C}_{3} \mathrm{~F}_{7} \mathrm{H}: 12.0$, HF:2.0.

Falloff behavior for the thermal decomposition reactions in the HFP mechanism was estimated, since low-pressure kinetic studies were not always available for analogous hydrocarbon reactions. For the low-pressure Arrhenius parameters, the activation energy was assumed to be identical to that in the high-pressure limit. The preexponential factor was chosen such that 
at a temperature of $1600 \mathrm{~K}$, the transition between low-pressure and high-pressure behavior occurs at $1.5 \mathrm{~atm}$ for $\mathrm{C}_{2}$ species (in nitrogen) and $0.3 \mathrm{~atm}$ for $\mathrm{C}_{3}$ species. Kinetics in the transition region were assumed to follow the Lindemann form. Third-body efficiencies relative to nitrogen were the same used for the fluoromethane decomposition reactions in Ref. 7. For HFP itself, a third-body efficiency of 12 was used.

Calculations of the experimental burner-stabilized flames were performed using the experimental temperature profiles as input. Multicomponent viscosities (the keyword MULT in the PREMIX code) and thermal diffusivities for $\mathrm{H}$ and $\mathrm{H}_{2}$ (TDIF keyword) were used to calculate species transport. The computational domain extended from the burner surface to $5 \mathrm{~cm}$. Mesh refinement tolerances (local/global variation) for the species profiles were set to 0.1 for the species concentrations (GRAD parameter in PREMIX) and to 0.25 for the concentration gradients (CURV parameter). The final grid for the uninhibited flame contained approximately 80 mesh points, while the solutions for the inhibited flames contained approximately 110 mesh points.

\section{TEMPERATURE PROFILES}

Flame temperatures were determined from rotational energy distributions of the $\mathrm{OH}$ radical by exciting the A-X $(1,0)$ band near $281 \mathrm{~nm}$. For the temperature measurements, the laser energy was attenuated to $<1 \mu \mathrm{J}$ to avoid saturation. A broadband UV Filter (Corning 7-54) was used to collect fluorescence on both the $(1,1)$ and $(0,0)$ transitions. Spectral scans comprising typically between $10-40$ spectral lines covering a broad range of rotational energies were performed at 15 points in each of the flame conditions used. Statistical uncertainties in the temperature fits ranged from $20-45 \mathrm{~K}$. Burner surface temperatures were measured by an uncoated type K (Chromel-Alumel) thermocouple. For the PREMIX calculations and in conversion of LIF data to species mole fractions, flame temperature profiles were represented by the (empirical) functional form

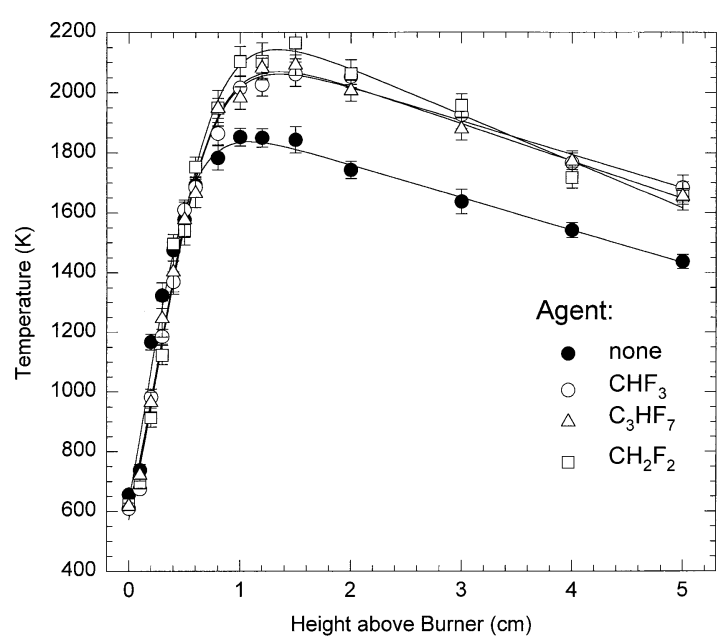

Fig. 1. Temperature profiles of the flames studied. Individual data points were determined from LIF spectra of $\mathrm{OH}$; statistical uncertainties are shown. Solid lines indicate functional fits (Eq. 1) which were used as inputs to PREMIX calculations and in converting LIF profiles into relative mole fractions.

$$
T(x)=\frac{A}{1+B \exp \left(\frac{x-C}{D}\right)}-E x
$$

where $x$ is the height above the burner in $\mathrm{cm}$. The coefficients $A-E$ were fit to the experimental data points. The fitted functions were used as temperature inputs to the PREMIX calculations, and for converting fluorescence intensity profiles to species mole fractions.

Temperature measurements and fitted functions are shown in Fig. 1 for the HFP-inhibited flame and, for comparison, the uninhibited flame as well as the flames inhibited by $\mathrm{CHF}_{3}$ and $\mathrm{CH}_{2} \mathrm{~F}_{2}$. The temperature profile of the flame containing HFP is nearly indistinguishable from that containing trifluoromethane at an equal loading of fluorine atoms.

\section{EMISSION PROFILES}

The methane/oxygen flame becomes markedly brighter upon addition of HFP. Profiles of $\mathrm{CH}^{*}$ emission at $430 \mathrm{~nm}$ are shown in the bottom panel of Fig. 2. The flame inhibited by HFP has twice the luminescence of the flame inhibited by $\mathrm{CHF}_{3}$, which in turn is slightly more than three times as luminous as the uninhibited flame. In 

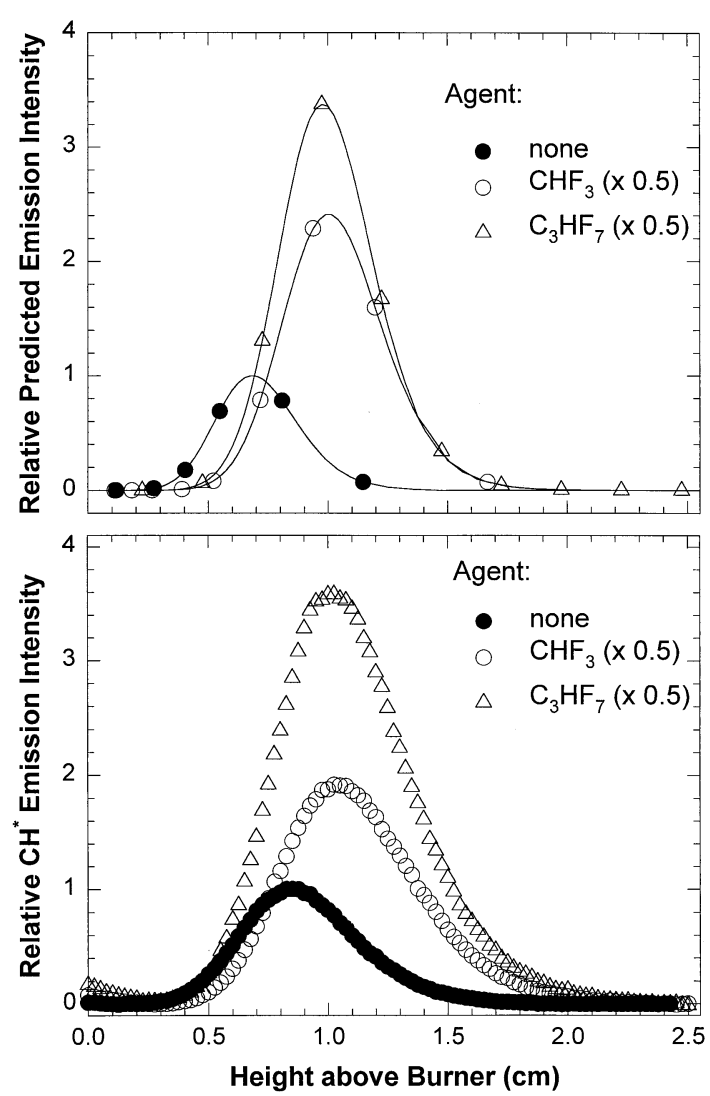

Fig. 2. $\mathrm{CH}^{*}$ emission profiles (bottom) at $430 \pm 10 \mathrm{~nm}$ for the uninhibited flame and the flames inhibited by $\mathrm{CHF}_{3}$ and HFP. Profiles for the inhibited flames have been reduced by a factor of 2. Emission profiles (top) estimated from the PREMIX calculation by taking the product of the $\mathrm{O}$ atom and $\mathrm{C}_{2} \mathrm{H}$ concentrations.

the top panel of Fig. 2, $\mathrm{CH}^{*}$ emission is estimated from the kinetics calculations by taking the product of the $\mathrm{C}_{2} \mathrm{H}$ and $\mathrm{O}$ atom concentrations [7], since the $\mathrm{C}_{2} \mathrm{H}+\mathrm{O}$ reaction is thought to be primarily responsible for $\mathrm{CH}$ chemiluminescence. The peak value of this product compared to the uninhibited flame is quite close to the experimental ratio of the emission intensities. The kinetic model predicts that formation of $\mathrm{C}_{2} \mathrm{H}$ in the HFP-inhibited flame occurs, as it does in flames containing fluoromethanes, through recombination of fluorinated methyl radicals with $\mathrm{CH}_{3}$. The fact that HFP forms $\mathrm{C}_{2}$ species in its initial decomposition steps does not account for the greater luminescence than in the $\mathrm{CHF}_{3}$-inhibited flame. Rather, the fraction of $\mathrm{CF}_{3}$ radicals that react with $\mathrm{CH}_{3}$ is
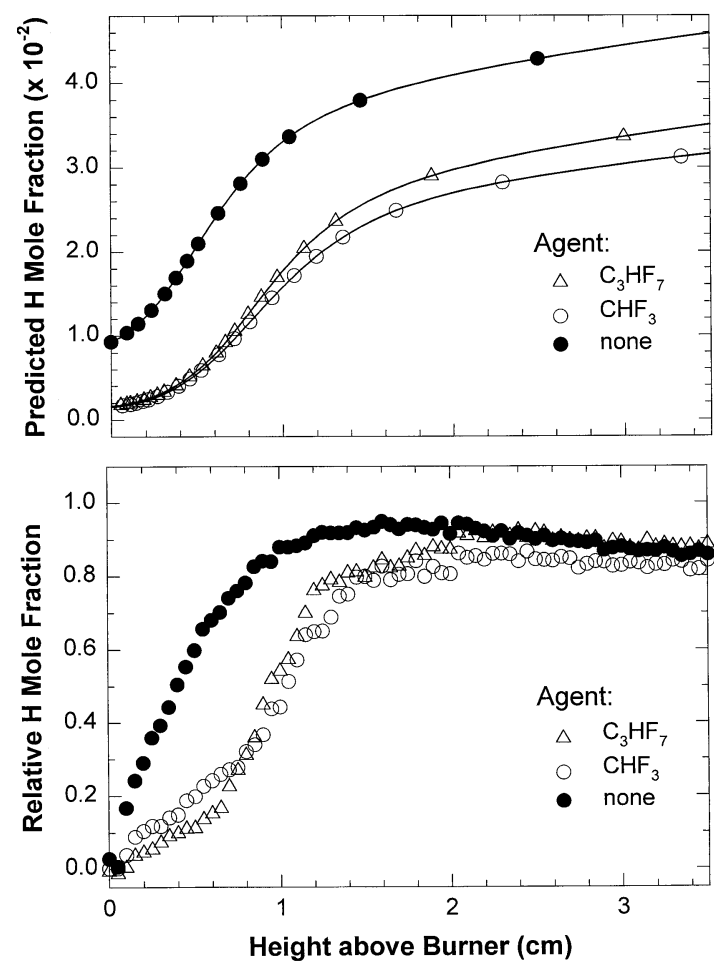

Fig. 3. Calculated (top) and measured (bottom) $\mathrm{H}$ atom profiles for the uninhibited flame, and the flames inhibited by $\mathrm{CHF}_{3}$ and HFP.

greater in the HFP flame because the agent's decomposition proceeds more quickly, leading to a better spatial overlap between the profiles of the two radicals. Also, HFP produces significant quantities of the partially fluorinated methyl radicals $\mathrm{CH}_{2} \mathrm{~F}$ and $\mathrm{CHF}_{2}$, whose recombination with $\mathrm{CH}_{3}$ in flames inhibited by $\mathrm{CH}_{3} \mathrm{~F}$ and $\mathrm{CH}_{2} \mathrm{~F}_{2}$ leads to greater $\mathrm{CH}^{*}$ chemiluminescence (at constant equivalence ratio and $\mathrm{F}: \mathrm{H}$ ratio) than in the $\mathrm{CHF}_{3}$-inhibited flame.

\section{LIF PROFILES OF INTERMEDIATE SPECIES}

Calculated and experimental profiles of $\mathrm{H}$ atom and $\mathrm{OH}$ are shown in Figs. 3 and 4, respectively. As with the temperature profile, the profiles of both these species are virtually identical between the flame inhibited by HFP and that inhibited by $\mathrm{CHF}_{3}$ at an equal loading of fluorine atoms. The profiles of these two radicals are also nearly identical for the flames contain- 

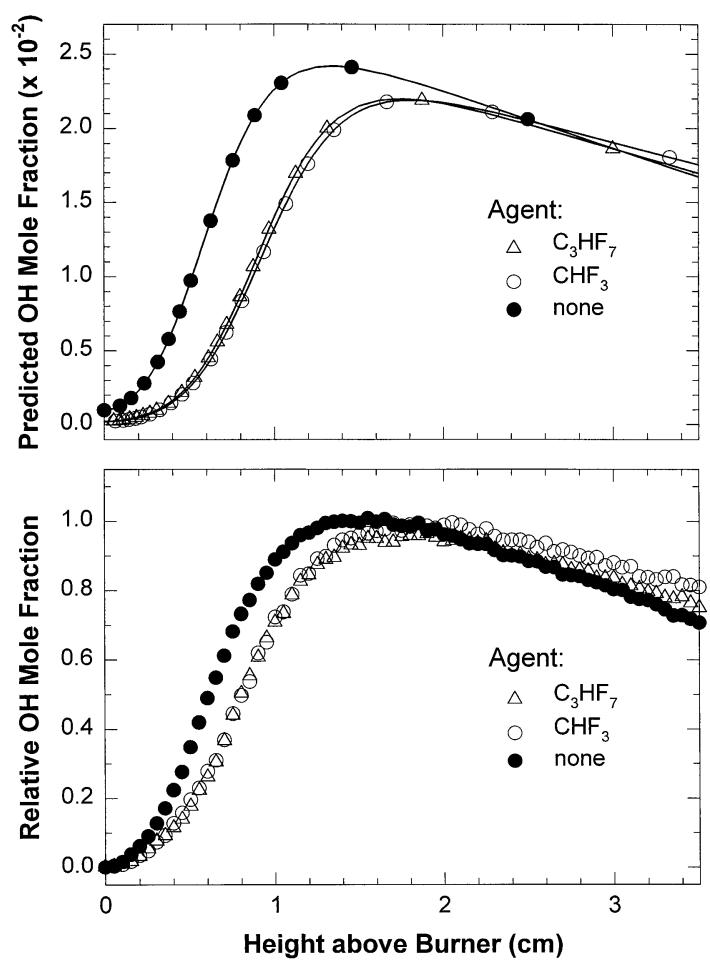

Fig. 4. Calculated (top) and measured (bottom) $\mathrm{OH}$ profiles for the uninhibited flame, and the flames inhibited by $\mathrm{CHF}_{3}$ and HFP.

ing mono- and difluoromethane as for trifluoromethane [7]. The kinetic modeling also predicts the close similarity of the $\mathrm{H}$ and $\mathrm{OH}$ profiles between the flames inhibited by $\mathrm{CHF}_{3}$ and HFP.

Calculated and experimental profiles of $\mathrm{CH}$ are shown in Fig. 5. The location of the $\mathrm{CH}$ mole fraction peak is nearly identical between the flames inhibited by HFP and by $\mathrm{CHF}_{3}$, but the flame containing HFP has a slightly higher peak $\mathrm{CH}$ concentration. The calculation predicts that the $\mathrm{CH}$ peak occurs slightly earlier in the HFP-inhibited flame than in the $\mathrm{CHF}_{3}-$ inhibited flame. The $\mathrm{CH}$ concentrations in the two inhibited flames, both relative to each other and to the uninhibited flame, are predicted quite well by the kinetic mechanism. The additional $\mathrm{CH}$ predicted to be formed from HFP is produced primarily from ${ }^{1} \mathrm{CH}_{2}$ and $\mathrm{CHF}$, which are produced in turn from $\mathrm{CH}_{2} \mathrm{~F}$ and $\mathrm{CHF}_{2}$.

Profiles of CHF are shown in Fig. 6. The CHF profile in the $\mathrm{CH}_{2} \mathrm{~F}_{2}$-inhibited flame is used as a

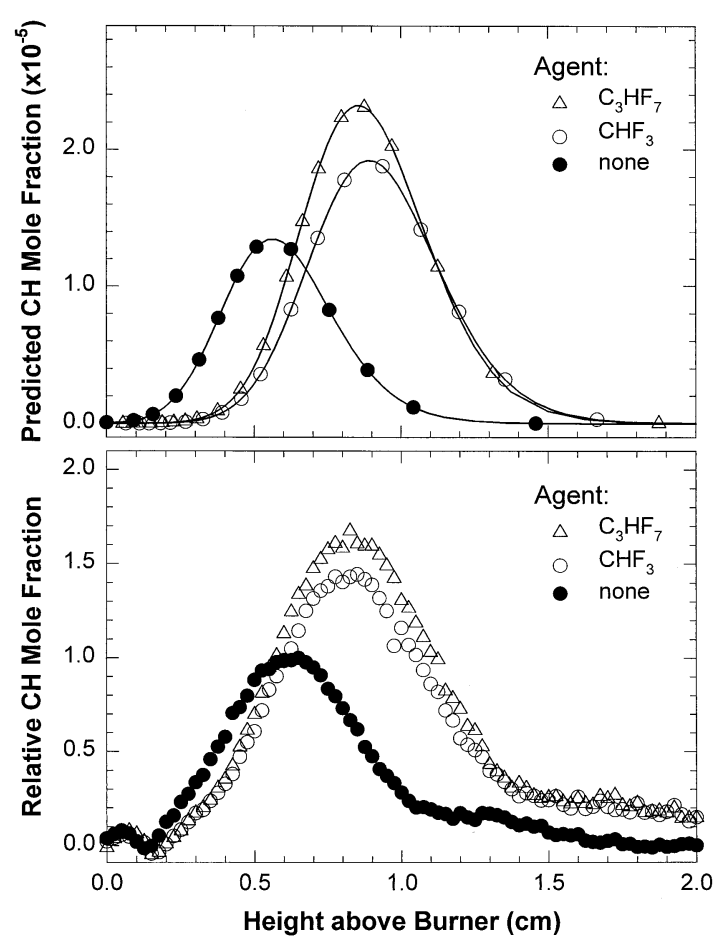

Fig. 5. Calculated (top) and measured (bottom) $\mathrm{CH}$ profiles for the uninhibited flame, and the flames inhibited by $\mathrm{CHF}_{3}$ and HFP.

reference for the HFP-inhibited flame, because no detectable LIF signal for this species was observed in the $\mathrm{CHF}_{3}$-inhibited flame. The LIF profile for this species suffers from interference in the luminous zone of the flame, as well as a large and ill-defined temperature correction [7]. For these reasons, there is a great deal of uncertainty in the location of the maximum CHF concentration. The experimental data do indicate a significant production of $\mathrm{CHF}$ in the HFP-inhibited flame, roughly $20-30 \%$ that of the $\mathrm{CH}_{2} \mathrm{~F}_{2}$-inhibited flame. The kinetic model predicts significant $\mathrm{CHF}$ production, in agreement with the experimental data. Analysis of the kinetic pathways (see below) indicates that $\mathrm{CHF}_{2}$ and $\mathrm{CH}_{2} \mathrm{~F}$ are predicted to be the primary precursors to $\mathrm{CHF}$.

Figures 7 and 8 show profiles of $\mathrm{CF}_{2}$ and $\mathrm{CF}$, respectively. The concentrations of these species in the HFP-inhibited flame relative to the $\mathrm{CHF}_{3}$-inhibited flame are predicted fairly well. The $\mathrm{CF}_{2}$ peak occurs earlier in the HFP-inhib- 

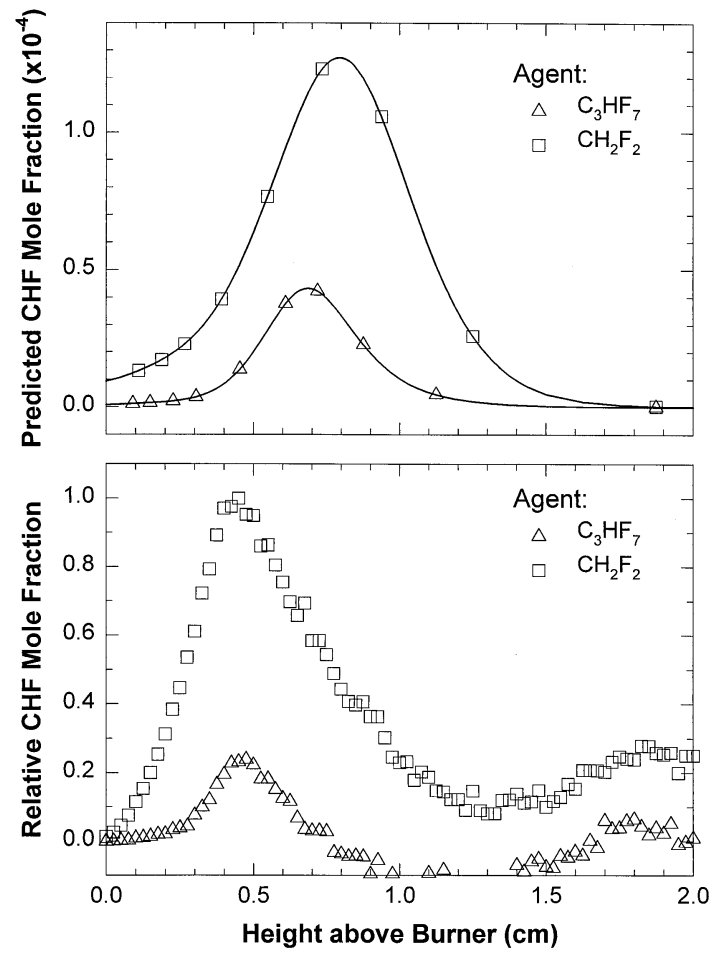

Fig. 6. Calculated (top) and measured (bottom) profiles of $\mathrm{CHF}$ for the flames inhibited by $\mathrm{CH}_{2} \mathrm{~F}_{2}$ and HFP. The flame inhibited by $\mathrm{CH}_{2} \mathrm{~F}_{2}$ was used for reference since no $\mathrm{CHF}$ signal was observed in the flame inhibited by $\mathrm{CHF}_{3}$. Near $1.0 \mathrm{~cm}$ the profiles may have been affected by saturation of the detector due to flame emission.

ited flame, which the model predicts although the profile shapes do not match exactly. The location of the CF mole fraction peak is slightly too far from the burner; this also occurs in the model prediction of all the flames inhibited by $\mathrm{C}_{1}$ fluorocarbons.

When reaction (R19) was added to the mechanism, the peak mole fraction of $\mathrm{CF}_{2}$ was overpredicted in the HFP-inhibited flame. Analysis of the reaction pathways indicated that $\mathrm{CHF}$ : $\mathrm{CF}_{2}$ produced by (R19) should be destroyed almost exclusively by the reaction

$$
\mathrm{CHF}: \mathrm{CF} 2+\mathrm{H} \Rightarrow \mathrm{CH}_{2} \mathrm{~F}+\mathrm{CF}_{2} \text {. }
$$

It is likely that attack by $\mathrm{O}$ and $\mathrm{OH}$ contribute more to this species' removal than the mechanism predicts. We added additional channels for these reactions (R3-20-R3-23), significantly improving agreement of the model with the experimental $\mathrm{CF}_{2}$ profiles.

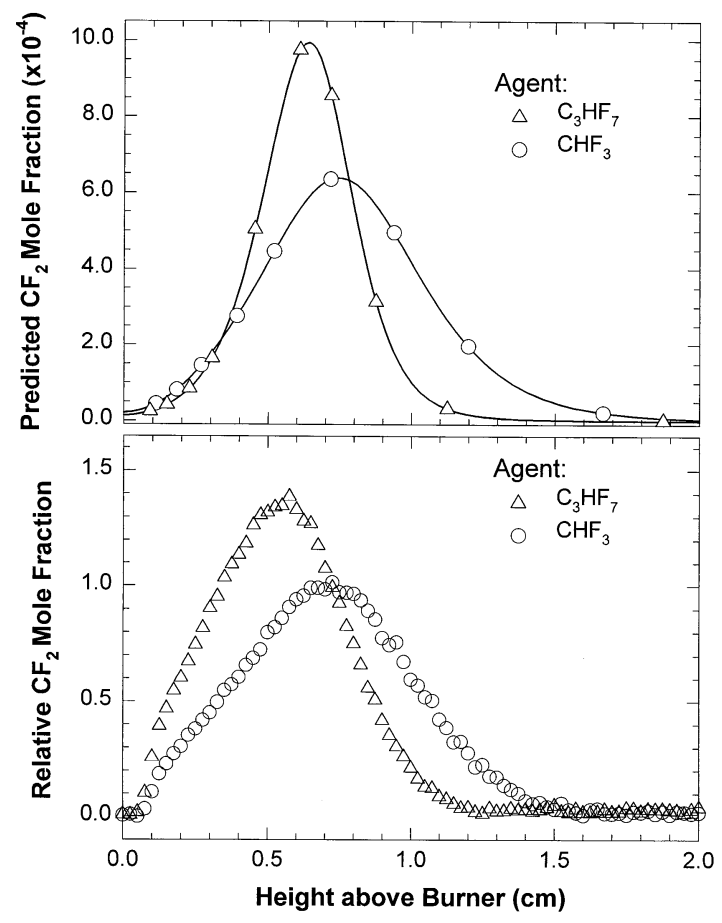

Fig. 7. Calculated (top) and measured (bottom) $\mathrm{CF}_{2}$ profiles for the flames inhibited by $\mathrm{CHF}_{3}$ and HFP.

\section{KINETIC PATHWAYS AND MECHANISM REFINEMENT}

Kinetic pathways are shown in Fig. 9. Arrow thicknesses between the different fluorocarbon species are proportional to the molar flux integrated across the flame. In some cases, incoming and outgoing arrow thicknesses do not sum to zero when, for instance, a $\mathrm{C}_{3}$ species breaks up into smaller fragments. The predicted reaction pathways in our flame conditions are considerably different than those presented by Hynes et al. in Ref. 8. In our $\mathrm{CH}_{4} / \mathrm{O}_{2}$ flames, thermal decomposition dominates agent destruction, even after falloff kinetics are added to the decomposition reactions. This is in contrast to the finding of Hynes et al., where hydrogen abstraction was predicted to account for the majority of agent destruction. The flame studied in Ref. 8 (hydrogen/air with equivalence ratios between 0.3 and 0.5 ) had low peak temperatures but high radical concentrations. In the present conditions, $\mathrm{H}$ atom abstraction from HFP (primarily by $\mathrm{OH}$ ) accounts for only about $5 \%$ of agent destruction. We initially modeled the 


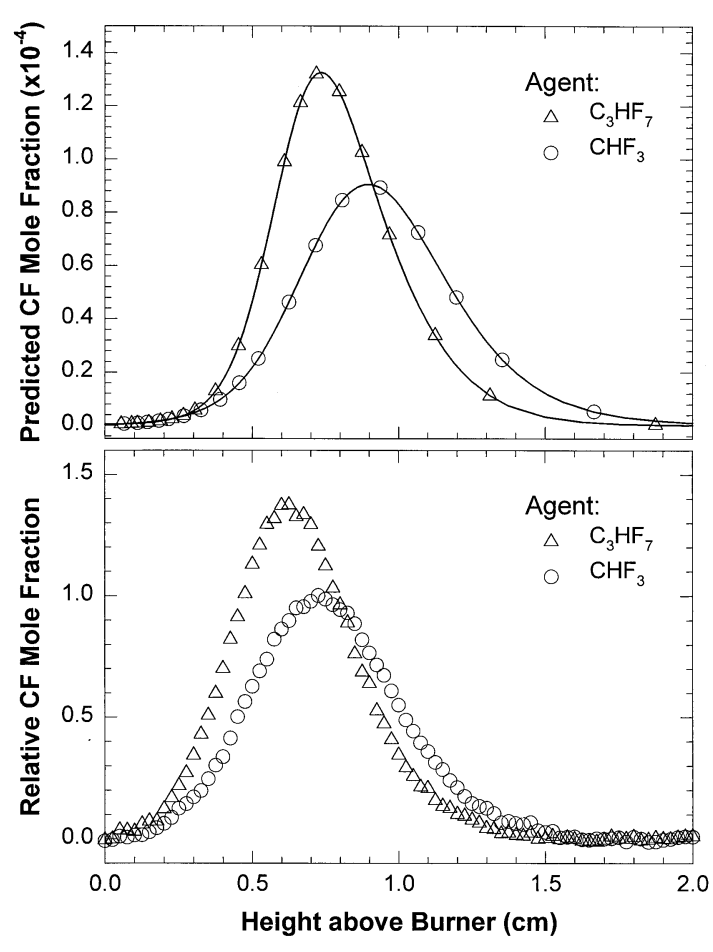

Fig. 8. Calculated (top) and measured (bottom) CF profiles for the flames inhibited by $\mathrm{CHF}_{3}$ and HFP.

flame using the HFP mechanism of Ref. 8, which led to the prediction that HF elimination (R3-2) predominates over C-C scission (R3-1) in destroying HFP. When the kinetic expressions from Ref. 9 are used for (R3-1) and (R3-2), the calculation now shows that C-C dissociation accounts for almost $90 \%$ of agent removal.

The $\mathrm{CF}_{3}-\mathrm{CHF}$ radical produced by (R3-1) is predicted to be removed primarily by two reactions, neither of which was included in the original HFC mechanism or in the kinetic model used in Ref. 8. Thermal dissociation to eliminate an $\mathrm{F}$ atom from the $\mathrm{CF}_{3}$ group (R319 ) is the dominant removal mechanism. For this reaction we use the parameters from Ref. 9 with estimated falloff behavior. The HFC mechanism includes thermal decomposition reactions for fluorinated ethyl radicals involving $\mathrm{C}-\mathrm{H}$ bond dissociation, but not $\mathrm{C}-\mathrm{F}$ dissociation, the most likely process if the molecule contains a $\mathrm{CF}_{3}$ group. It seems likely that analogous reactions should be added to the HFC mechanism for other fluoroethyl radicals. Reaction with $\mathrm{H}$ atom (R3-17) is predicted to be a secondary process in $\mathrm{CF}_{3}-\mathrm{CHF}$ destruction. The reaction of $\mathrm{CF}_{3}-\mathrm{CHF}$ with $\mathrm{OH}$ to produce $\mathrm{CF}_{2} \mathrm{CO}$, which Ref. 8 predicted to be the dominant removal reaction, is of minor importance under our conditions when (R3-17) and (R3-19) are considered.

The removal reactions of $\mathrm{CHF}: \mathrm{CF}_{2}$ are another area of the mechanism which appears to require attention. The inclusion of (R3-19) greatly increases the importance of this species in the kinetic pathways of HFP. When this reaction was added, predictions of flame speeds (discussed below) were greatly improved, but the concentration of $\mathrm{CF}_{2}$ was overpredicted. The removal of $\mathrm{CHF}: \mathrm{CF}_{2}$ was predicted to almost exclusively by reaction (R1), which accounts for the overprediction of $\mathrm{CF}_{2}$. This reaction is endothermic by about $10 \mathrm{kcal} / \mathrm{mol}$; the alternative product channel, $\mathrm{CHF}_{2}+\mathrm{CHF}$, is too endothermic to be significant.

Reactions of $\mathrm{CHF}: \mathrm{CF}_{2}$ with $\mathrm{O}$ and $\mathrm{OH}$ are assumed in the HFC model to proceed by analogous pathways to those for ethylene [19],

$$
\begin{aligned}
& \mathrm{CHF}: \mathrm{CF}_{2}+\mathrm{O} \Rightarrow \mathrm{CFO}+\mathrm{CHF}_{2} \\
& \mathrm{CHF}: \mathrm{CF}_{2}+\mathrm{OH} \Rightarrow \mathrm{CF}_{2}: \mathrm{CF}+\mathrm{H}_{2} \mathrm{O} .
\end{aligned}
$$

It seems plausible that other channels may become more important as the ethylene becomes progressively more fluorinated. For the reaction of $\mathrm{O}$ atom with $\mathrm{C}_{2} \mathrm{~F}_{4}$, the products are $\mathrm{COF}_{2}+\mathrm{CF}_{2}$. We have postulated (R3-20) and (R3-21) as analogous product channels for the $\mathrm{O}$ atom reaction with trifluoroethylene. For the reaction of $\mathrm{OH}$ with ethylenes, $\mathrm{H}$ atom abstraction was the only product channel considered [19]. Reaction (R3) is essentially isothermic, and it appears that addition may be a more likely mechanism for $\mathrm{OH}$ attack on a heavily fluorinated ethylene. This possibility was not included in the HFC mechanism, partly because one possible set of products (following $\mathrm{HF}$ elimination) would be fluorinated vinoxy radicals, which are currently not included in the mechanism [19]. In (R3-22) and (R3-23) products are assumed to be a fluorinated methyl radical and a fluorocarbonyl (which could result from $\mathrm{H}$ atom migration followed by $\mathrm{C}-\mathrm{C}$ bond rupture after the initial addition). This choice of products is motivated in part to avoid introduc- 


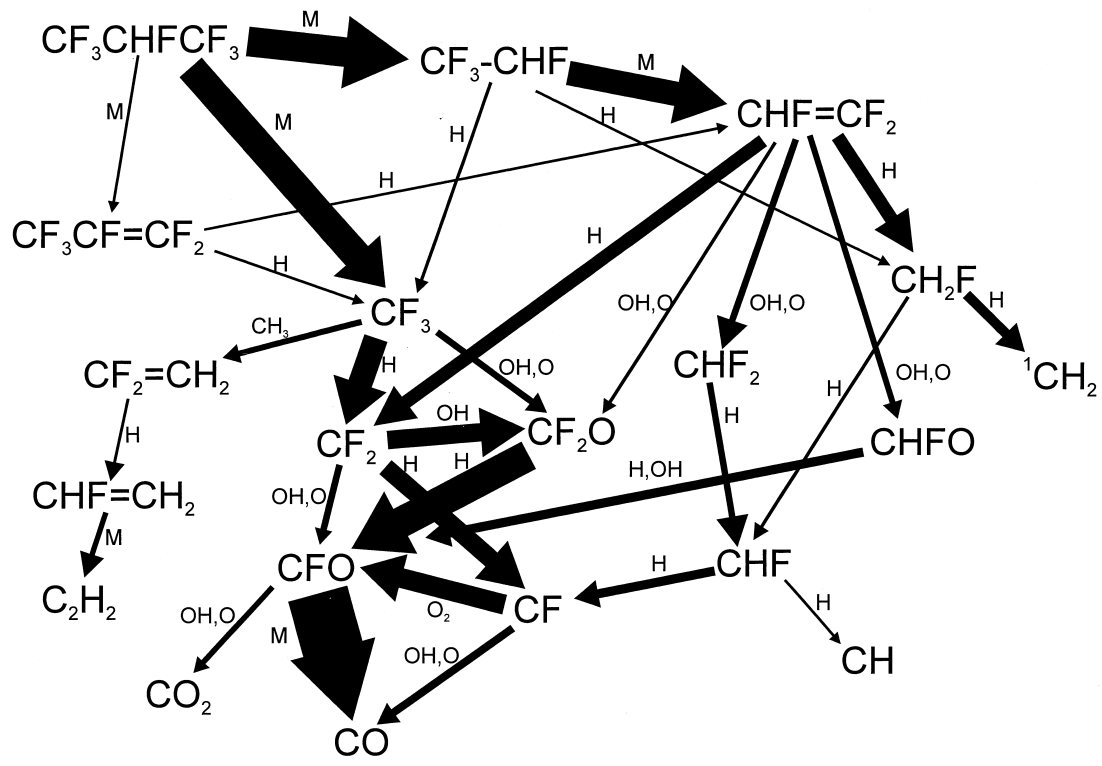

Fig. 9. Reaction pathways of fluorocarbon species in the $\mathrm{CH}_{4} / \mathrm{O}_{2} / \mathrm{C}_{3} \mathrm{HF}_{7}$ flame according to the kinetic mechanism. Arrow thicknesses are proportional to the molar flux of carbon-containing species. The most important reaction partner(s) are written next to each arrow in decreasing order of importance.

ing additional species into the mechanism. Both reactions are significantly exothermic.

Addition of (R3-20)-(R3-23) corrected the discrepancy in the $\mathrm{CF}_{2}$ profile predictions caused by the addition of (R3-19). The flame profile data indicates that $\mathrm{CHF}: \mathrm{CF}_{2}$ reacts significantly with some species besides $\mathrm{H}$, but it does not prove that the kinetics and products we have postulated are correct. In Ref. 19 it was remarked that consideration of additional product channels for the $\mathrm{O}$ and $\mathrm{OH}$ reactions with fluoroethylenes would be desirable at a subsequent stage of validation. We concur with this view in light of the importance of fluoroethylenes in the kinetic pathways of HFP and probably other fluoroethanes and fluoropropanes as well.

\section{ATMOSPHERIC PRESSURE FLAME SPEED CALCULATIONS}

Linteris et al. [12] published flame speed measurements of atmospheric pressure methane/air mixtures inhibited by HFP as well as other fluorinated ethanes and fluorinated propanes. Comparisons with calculations using the NIST HFC mechanism were reported for the fluorinated ethanes. No comparisons with model predictions were reported for HFP.

As an additional test of the HFP submecha- nism, we performed flame speed calculations in comparison to the data of Linteris et al. [12]. Calculations were performed for flames containing mole fractions of approximately 3\% HFP in methane/air mixtures with $\mathrm{CH}_{4} / \mathrm{O}_{2}$ ratios of $0.45,0.50$, and 0.55 . The flame speed calculations were performed on a domain extending $25 \mathrm{~cm}$ from the flame on the cold boundary, and $60 \mathrm{~cm}$ on the hot boundary. The calculations used multicomponent viscosities, thermal diffusion for $\mathrm{H}$ and $\mathrm{H}_{2}$, and windward differencing on the convective term. The initial temperature of the fresh gases was set to 298.2 $\mathrm{K}$. The solutions were obtained on meshes having 150 grid points. Previously, we used the same kinetic mechanism employed here (without the HFP submechanism) to calculate flame speeds of $\mathrm{CH}_{4} / \mathrm{air} / \mathrm{CHF}_{3}$ and $\mathrm{CH}_{4} / \mathrm{air} / \mathrm{CH}_{2} \mathrm{~F}_{2}$ mixtures [7]; good agreement with experimental data was obtained for all conditions except for difluoromethane-inhibited flames at high equivalence ratios $(\phi>1.25)$.

In initial calculations, predicted flame speeds in the three HFP-inhibited mixtures were far too low, ranging from $40 \%$ to $70 \%$ of the experimental values. Sensitivity and reaction pathway analysis indicated that thermal decomposition should dominate HFP removal, and that predominance of $\mathrm{C}-\mathrm{C}$ bond dissociation as opposed to $\mathrm{HF}$ elimination should increase 
TABLE 4

Calculated Flame Speeds of $\mathrm{CH}_{4} / \mathrm{air} / \mathrm{CF}_{3} \mathrm{CHFCF}_{3}$ Mixtures

\begin{tabular}{cccccccr}
\hline & & \multicolumn{2}{c}{ Calculation } & & \multicolumn{2}{c}{ Experiment $^{\mathrm{b}}$} \\
\cline { 3 - 5 } $\mathrm{CH}_{4} / \mathrm{O}_{2}$ ratio & HFP mole $\%$ & $U(\mathrm{~cm} / \mathrm{s})$ & $U / U_{o}{ }^{a}$ & & $U$ & $U / U_{o}$ & $\left(U / U_{o}\right)_{\mathrm{calc}} /\left(U / U_{o}\right)_{\mathrm{exp}}$ \\
\hline 0.45 & 2.96 & 17.76 & 0.50 & 22.8 & 0.61 & 0.83 \\
0.50 & 2.93 & 16.27 & 0.41 & 15.4 & 0.37 & 1.11 \\
0.55 & 2.91 & 12.32 & 0.31 & 17.4 & 0.44 & 0.70 \\
\hline
\end{tabular}

${ }^{a}$ Speed normalized by speed of uninhibited $\mathrm{CH}_{4} /$ air flame at same $\mathrm{CH}_{4} / \mathrm{O}_{2}$ ratio.

${ }^{b}$ Ref. 12 .

flame speed. This effect is presumably due to the creation of two radicals by (R3-1), as opposed to two stable species by (R3-2). In Ref. 9 Hynes et al. derived new rate expressions for the HFP decomposition reactions, and added (R319) for $\mathrm{CF}_{3}-\mathrm{CHF}$ removal. The revised kinetic parameters for (R3-1) and (R3-2) greatly increased the predicted predominance of C-C bond rupture in HFP removal, and led to flame speed predictions $1-2 \mathrm{~cm} / \mathrm{s}$ higher.

The addition of (R3-19) caused a much larger increase in the predicted flame speed for all stoichiometries. The $\mathrm{F}$ atom generated by this reaction reacts predominantly with water to yield $\mathrm{HF}+\mathrm{OH}$, generating one of the important flame radicals. Addition of Reactions (R320)-(R3-23) did not significantly affect the predicted flame speed. Using the final mechanism as detailed in Table 1, the calculated flame speed results are given in Table 4 . The predictions agree with the experimental data within $30 \%$ for all three test cases. The prediction is least accurate for the rich stoichiometry, where formation of larger HFC species not included in the present mechanism is most likely to be most important.

One unusual aspect of the experimental flame speed measurements reported by Linteris et al. was that at a fixed agent concentration, HFP caused a greater reduction in flame speed for the 0.50 methane/oxygen ratio than for the 0.55 ratio. By contrast, all other HFCs agent tested caused a progressively greater reduction in burning velocity as the methane/oxygen ratio was increased between 0.45 and 0.55 . Our calculation does not predict the behavior observed experimentally for HFP; rather, it predicts that the inhibition effectiveness becomes progressively greater as the stoichiometry becomes richer.
It is noteworthy that in Ref. 12, burning velocities were significantly underpredicted for mixtures inhibited by $\mathrm{CF}_{3}-\mathrm{CH}_{2} \mathrm{~F}$ and $\mathrm{CF}_{3^{-}}$ $\mathrm{CHF}_{2} \cdot \mathrm{CF}_{3}-\mathrm{CH}_{2} \mathrm{~F}$ is largely converted to $\mathrm{CF}_{3}-$ $\mathrm{CHF}$ by hydrogen abstraction, while $\mathrm{CF}_{3}-\mathrm{CHF}_{2}$ forms $\mathrm{CF}_{3}-\mathrm{CF}_{2}$. Based on the current modeling results for HFP, the addition of Reaction (R319) and an analogous decomposition for $\mathrm{CF}_{3}$ $\mathrm{CF}_{2}$ should significantly increase the predicted flame speeds from the values obtained in Ref. 12 , improving agreement with the experimental measurements.

\section{DISCUSSION}

The agreement between the experimental intermediate species data and the predictions of the kinetic model is quite good. There is a slight discrepancy in the predictions of $\mathrm{CF}_{2}$ profiles, suggesting that removal kinetics of fluorinated ethylenes by $\mathrm{O}$ and $\mathrm{OH}$ require further investigation. The addition of Reactions (R3-20)-(R323) was the only change made to the mechanism on the basis of improving the fit to the experimental profiles. No changes whatsoever were made to the $\mathrm{C}_{1}$ fluorocarbon kinetics, because predictions of fluoromethane-inhibited flame structures are sensitive to these reactions, and any alterations would have to be validated against the data modeled in Ref. 7.

The kinetics of the HFP and $\mathrm{CF}_{3}-\mathrm{CHF}$ thermal decomposition reactions given in Ref. 9 greatly improve predictions of burning velocities; we have adopted these rate expressions for this reason. In Ref. 9 additional reactions and species were included in the kinetic mechanism which were not included in Ref. 8. We have not incorporated these into our mechanism since they are likely to be less important in a near- 
stoichiometric flame than in a purely pyrolytic environment. It is possible, however, that for rich stoichiometries or higher inhibitor concentrations these may need to be considered. The $\mathrm{C}_{3}$ reaction set used here is minimal in size compared to the $\mathrm{C}_{2}$ reactions in the NIST HFC mechanism and it should not be considered as being comprehensive.

To investigate the applicability of the mechanism given here to the conditions of Hynes et al., we modeled the conditions of Ref. 10 using the experimental temperature profile as input. The model calculations of species profiles were qualitatively similar to those obtained by Hynes et al. There were some differences; in particular the $\mathrm{COF}_{2}$ concentration was calculated to be about $30 \%$ higher as a result of our modifications to the $\mathrm{C}_{1}$ kinetics in Ref. 7. Hynes et al. measured somewhat lower concentrations of this species in the postflame zone than were predicted by their mechanism. Secondary reactions (hydrolysis in particular) of $\mathrm{COF}_{2}$ following probe sampling may, however, account for the discrepancy [8]. The differences in the mechanisms between that used here and that of Ref. 10 had a much smaller effect on the species profiles than did the perturbations introduced by the sampling probe, which Hynes et al. treated phenomenologically. The experimental data presented in [10] does not appear to unequivocally favor either mechanism over the other.

The agreement of the modeling predictions using the current mechanism with the species profiles is very encouraging since there are significant differences in stoichiometry, pressure, and temperature between the present experiment and the conditions studied by Hynes et al. The present data set is only an indirect measure of the initial HFP decomposition pathways, since all the species monitored are several reactions removed from the original agent. Other sets of validation data are desirable to experimentally verify the kinetic pathways of HFP in flames.

In terms of refinements to the HFC mechanism, it appears that thermal decomposition reactions of fluoroethyls to produce atomic fluorine are important and need to be added. This is likely to have implications for modeling inhibition by $\mathrm{C}_{2}$ as well as $\mathrm{C}_{3}$ agents. Revision of $\mathrm{O}$ and $\mathrm{OH}$ reaction kinetics with fluoroethylenes will impact flame structure calculations, but appears to have little effect on global parameters such as flame speed.

We thank Robert Hynes for his helpful discussions and for sharing with us the thermodynamic, transport, and kinetic parameters for the HFP submechanism. This work was supported by the U.S. Naval Sea Systems Command.

\section{REFERENCES}

1. Miziolek, A. W., and Tsang, W., Eds., Halon Replacements: Technology and Science, ACS Symposium Series 611, American Chemical Society, Washington, DC, 1994.

2. Sheinson, R. S., Penner-Hahn, J. E., and Indritz, D., Fire Safety J. 15:437-450 (1989).

3. Nyden, M. R., Linteris, G. T., Burgess, Jr., D. R. F., Westmoreland, P. R., Tsang, W., and Zachariah, M. R., in Evaluation of Alternative In-Flight Fire Suppressants for Full-Scale Testing in Simulated Aircraft Engine Nacelles and Dry Bays (W. L. Grosshandler, R. G. Gann, and W. M. Pitts, Eds.), NIST SP 861, 1994, pp. 467-642.

4. Westmoreland, P. R., Burgess, Jr., D. R. F., Zachariah, M. R., and Tsang, W., Twenty-Fifth Symposium (International) on Combustion, The Combustion Institute, Pittsburgh, 1994, pp. 1505-1511.

5. Burgess, Jr., D. R. F., Zachariah, M. R., Tsang, W., and Westmoreland, P. R., Prog. Energy Combust. Sci. 21:453 (1996).

6. The current NIST HFC mechanism may be downloaded from http://fluid.nist.gov/ ckmech.html.

7. L'Espérance, D., Williams, B. A., and Fleming, J. W., Combust. Flame 117:709-731 (1999).

8. Hynes, R. G., Mackie, J. C., and Masri, A. R., Combust. Flame 113:554-565 (1998).

9. Hynes, R. G., Mackie, J. C., and Masri, A. R., J. Phys. Chem. A 103:54-61 (1999).

10. Hynes, R. G., Mackie, J. C., and Masri, A. R., Energ. Fuel 13:485-492 (1999).

11. Westbrook, C. K., Combust. Sci. Technol. 34:201 (1983).

12. Linteris, G. T., Burgess, Jr., D. R., Babushok, V., Zachariah, M., Tsang, W., and Westmoreland, P., Combust. Flame 113:164-180 (1998).

13. L'Espérance, D., Williams, B. A., and Fleming, J. W., Chem. Phys. Lett. 280:113-118 (1997).

14. Kee, R. J., Grcar, J. F., Smooke, M. D., and Miller, J. A., PREMIX: A Fortran Program for Modeling Steady Laminar One-Dimensional Premixed Flames, Sandia Report SAND85-8240, 1985.

15. Kee, R. J., Rupley, F. M., and Miller, J. A., ChemkinII: A Fortran Chemical Kinetics Package for the Analysis of Gas-Phase Chemical Kinetics, Sandia Report SAND89-8009, 1989. 
16. Kee, R. J., Warnatz, J., and Miller, J. A., A Fortran Computer Code Package for the Evaluation of GasPhase, Multicomponent Transport Properties, Sandia Report SAND83-8209, 1983.

17. Bowman, C. T., Hanson, R. K., Gardiner, W. C., Lissianski, V., Frenklach, M., Goldenberg, M., and Smith, G. P., GRI-Mech 2.11-An Optimized Detailed Chemical Reaction Mechanism for Methane Combustion and NO Formation and Reburning, GRI Report GRI-97/0020, 1997, Gas Research In- stitute, Chicago. http://www.ME.Berkeley.edu/ gri-mech/

18. Hynes, R., private communication.

19. Burgess Jr., D. R. F., Zachariah, M. R., Tsang, W., and Westmoreland, P. R., Thermochemical and Chemical Kinetic Data for Fluorinated Hydrocarbons, NIST Technical Note 1412 (1995).

Received 1 December 1998, revised 21 May 1999, accepted 8 June 1999 